\title{
Making Science Organizations Sustainable - The Mission of the Max Planck Sustainability Network
}

\begin{abstract}
Tanguy Fardet ${ }^{1 \dagger}$, Moritz Hütten ${ }^{2 \dagger}$, Sophie Lohmann ${ }^{3 \dagger}$, Evelyn Medawar ${ }^{4 * t}$, Jana Milucka ${ }^{5 t}$, Jan Harald Roesch ${ }^{6 \dagger}$, Julian D. Rolfes ${ }^{7 \dagger}$ and Jakob Schweizer ${ }^{8 \dagger}$

${ }^{1}$ Max Planck Institute for Biological Cybernetics, Tübingen, Germany, ${ }^{2}$ Gamma-ray Astronomy, Max Planck Institute for Physics, Munich, Germany, ${ }^{3}$ Laboratory of Digital and Computational Demography, Max Planck Institute for Demographic Research, Rostock, Germany, ${ }^{4}$ Department of Neurology, Max Planck Institute for Human Cognitive and Brain Sciences, Leipzig, Germany, ${ }^{5}$ Greenhouse Gases Research Group, Max Planck Institute for Marine Microbiology, Bremen, Germany, ${ }^{6}$ Max Planck Society, General Administration, Munich, Germany, ${ }^{7}$ Molecular Theory and Spectroscopy, Max-Planck-Institut für Kohlenforschung, Mülheim, Germany, ${ }^{8}$ Process Systems Engineering, Max Planck Institute for Dynamics for Complex Technical Systems, Magdeburg, Germany
\end{abstract}

OPEN ACCESS

Edited by: Jana Dlouhá,

Charles University, Czechia

Reviewed by:

Juana M. Rivera-Lirio,

University of Jaume I, Spain

Marcos Gonçalves Perroni,

Universidade Do Contestado, Brazil

*Correspondence:

Evelyn Medawar

info@susnet.mpg.de

http://www.sustainability-network.

mpg.de/

Twitter: @sustainable_mpg

${ }^{+}$Max Planck Sustainability Network

Specialty section:

This article was submitted to

Sustainable Organizations,

a section of the journal

Frontiers in Sustainability

Received: 29 May 2020

Accepted: 19 August 2020

Published: 25 September 2020

Citation:

Fardet T, Hütten M, Lohmann S, Medawar E, Milucka J, Roesch JH,

Rolfes JD and Schweizer J (2020)

Making Science Organizations Sustainable - The Mission of the Max

Planck Sustainability Network

Front. Sustain. 1:567211.

doi: 10.3389/frsus.2020.567211
The Max Planck Sustainability Network (MPSN) is a grassroots network within the Max Planck Society (MPG), with 370 members from over 60 Max Planck research institutes, aiming to support sustainability within a German science association committed to fundamental research. The MPSN has adopted the twin goals of making research practices within the overall MPG more sustainable and of supporting local Sustainability Groups in making research practices at their individual institutes more sustainable. The MPSN counts members from diverse backgrounds, regarding both academic field of expertise and roles within the MPG. Its activities focus around Energy, Mobility, Supplies and Waste, Biodiversity and Food, with the ambition to assess impact and expense of each proposed measure. The network's long-term vision is to make research more sustainable and to serve as a role model that inspires other scientific organizations to become sustainable and to optimize the operation of research and administration, which require both individual and structural changes.

Keywords: majority vote, Max Planck Society, moral responsibility, research organizations, non-scientific staff, scientific staff, grassroots network, sustainability science

\section{INTRODUCTION}

Since its foundation and first general meeting in May 2019, the Max Planck Sustainability Network (MPSN) has attracted over 370 members from over 60 Max Planck Institutes (Figure 1A). At over 30 of these institutes, local Sustainability Groups have also formed which are connected through the MPSN. This network aims to support sustainability within the Max Planck Society $(\mathrm{MPG})^{1}$, a German science association committed to fundamental research. The MPG holds more than 23,000 affiliated individuals in over 85 institutes, mainly located in Germany but also in Italy, the Netherlands, Luxemburg, and the USA. The MPG supports prominent research on various topics, including climate change, biodiversity, and societal challenges associated with sustainability or the lack thereof. Yet, the MPG currently operates much like most other academic institutions in that

${ }_{1}^{1}$ Max Planck Society for the Advancement of Science, German: Max-Planck-Gesellschaft zur Förderung der Wissenschaften e. V. 
research is largely conducted without assessing and addressing the ecological consequences of the materials, energy usage, and travel involved in the research process. The work performed in the MPG therefore does not only contribute to the scientific advancement of humankind, but also to anthropogenic emissions of greenhouse gases, waste generation, and depletion of resources. Indeed, if the scientific community has successfully made the first step-acknowledging that humanity is facing an environmental crisis-the second step-acting upon it within our own life and work-is needed. The members of the MPSN feel a moral obligation to address the ecological consequences of their work and to transition toward a more sustainable research environment. Transforming organizations toward more sustainable ones from the employer's perspective has received much interest recently, highlighting the importance of employee engagement (Kim et al., 2016), adapted strategic planning (Batista and Francisco, 2018) and conceptual frameworks to guide invested efforts (Lozano, 2018). The MPSN has therefore adopted the twin goals of making research practices within the overall MPG more sustainable and of supporting local Sustainability Groups in making research practices at their individual institutes more sustainable. The network's longterm vision is to become role models that inspire other scientific organizations to become sustainable and to optimize the operation of research and administration in the MPG toward a system that operates sustainably.

\section{SCIENTISTS' MORAL OBLIGATION}

\author{
"Insight must precede application." / "Dem Anwenden muss das \\ Erkennen vorausgehen." \\ -Max Planck
}

The reverse conclusion of Max Planck's quote implies that appropriate application must follow insight. This is especially true for those who have early and direct access to this insight. In the past years and decades, scientists have increasingly urgently called attention to the climate crisis and called for climate action from governments, industry, and citizens. To highlight two examples, over 15,000 scientists signed the "Warning of a climate emergency" (Ripple et al., 2020) and the "Scientists For Future" network is officially supported by 26,000 scientists in Germanspeaking areas alone (Hagedorn et al., 2019). Addressing the climate crisis and moving toward a sustainable world requires both, research on what is happening and how different problems could be solved, and concrete action and behavior change [see IPCC SR15 report; Rogelj et al. (2018)] —both knowledge and action are indispensable parts of sustainability. Yet, science also produces its share of global greenhouse gas emissions and other negative environmental impacts. On the global level and compared to other emitters such as energy suppliers or food producers, this share is relatively small. However, scientists' carbon footprint per capita is above average (Rosen, 2017; Jean and Wymant, 2019; Langin, 2019; Nature Nanotechnology., 2019). In consequence, many scientists do not only lobby for more climate action in society and politics but are also aiming to reduce their own carbon footprint (Rosen, 2017).
To make research environmentally friendly, scientists need to initiate a process of change management in scientific institutions. Moreover, making research processes more environmentally friendly, scientists' call for global climate action becomes more credible.

Implementing more sustainable practices in research will not be possible without behavioral change and thus limitations which could be perceived as restrictions. For example, the major contribution to the carbon footprint of science presumably is air travel activity (accounting for up to 50\% of emissions), especially to conferences (Jean and Wymant, 2019; Langin, 2019; Nature Nanotechnology., 2019; Klöwer et al., 2020). Here, the necessary action is to travel less and especially to fly less.

Such limitations are often criticized for being contradictory to the freedom of science (Vogt and Weber, 2020). Freedom of science refers to the idea that research questions and objectives are formulated by scientists and that the results cannot be influenced or even dictated. However, freedom of science does not imply that scientists can act without any limitations or restrictions. Science has always been and is subject to limitations and restrictions which are imposed by society and politics but also by their own administrations (Beringer and Adomßent, 2008; Bachmann, 2016). On the contrary, by being proactive, science organizations can ensure their own freedom of research. It is probable that society and politics aim to rather increase than decrease legal regulations with regard to aspects of sustainability. Thus, by developing own sustainability strategies, science organizations can either prevent legal regulations or at least contribute shaping them.

Finally, as citizens, scientists have a duty to act for the public good (Douglas, 2009)-because they are in a unique position to access the relevant knowledge, because they have the means to act, and because the credibility of the scientific message regarding the environmental crisis depends on scientists' action upon their own behavior. In consequence, colleagues of the MPG saw a moral obligation to advocate for sustainability in research and founded the Max Planck Sustainability Network for this purpose.

\section{INTERDISCIPLINARITY}

Interdisciplinary approaches are crucial in defining and enacting sustainable behaviors within a scientific context. Most importantly, research on sustainability-including climate and environmental research, social science studies on behavioral change, and research on new technologies-paves the way to a sustainable future. The MPSN approaches this goal by exchanging perspectives between multiple scientific disciplines and by assessing the impact of measures both during decision-making and during evaluation. However, beyond these fields with a directly obvious link to sustainability, other fields-even seemingly unrelated ones, such as law, art, or mathematics-provide research and perspectives that are beneficial to developing ideas with which to approach challenges to adopting climate-friendly practices. In the MPSN, the majority 
of members currently has a background in traditional natural sciences (Physics, Biology, Chemistry), but individuals from Neuroscience, Psychology, Medical Sciences, or Computer Science are also represented (in total Natural Sciences 85\%, Social Sciences 15\%; Figure 1B). Activities within the network are framed around the existing expertise in the MPG from climate-related research (featured on the MPSN website, invited talks, and seminars on climate topics), but also extend basic research, for example, discussing the psychology of climate beliefs and communication strategies for environmental sciences. Indeed, around one fourth of the scientific staff within the MPSN is currently or planning to do research on sustainability (Figure 1C).

Especially as affiliates of a scientific interdisciplinary research organization, MPSN members translate their collective multidisciplinary knowledge into finding solutions to more sustainable research practices. Much like society needs diverse voices to tackle the climate crisis, the MPSN represents all voices from different disciplines and from scientific backgrounds for impactful climate action.

\section{NON-HIERARCHICAL GRASSROOTS ACTION AND INCLUSIVITY}

To support sustainability in the MPG and enable interdisciplinary communication, members of the scientific community need to get together and exchange ideas for climate action. Although the support from institutions' leadership and governmental actors is important, climate action will be most effective if members of the scientific community begin organizing, discussing, proposing, and promoting climate action themselves, lobbying executive and legislative powers for changes in rules and regulations rather than passively waiting for such change to happen.

Thus, the MPSN was founded as a grassroots initiative, striving for maximum inclusivity and bottom-up processes and works accordingly by honorary engagement. The MPSN combines local Sustainability Groups from different Max Planck Institutes and a network-wide Steering Committee to foster communication. The statutes of the network are openly available. Official polls and elections are based on a majority judgment grading system (Balinski and Laraki, 2007), which is a recently developed method for finding a compromise in a democratic decisions process. The network is bilingual (German and English, because the network has an internationally diverse membership) and aims to be inclusive (e.g., non-binary, gender-inclusive communication) and non-hierarchical (e.g., through omitting academic titles). Members consider themselves pioneers of a sustainability movement in academia and engage in proposed measures, such as virtual meetings, voluntary self-commitments to fly less, cultivating eco-friendly green spaces at institutes, establishing waste sorting, and open sharing of resources. It is inherently important that both scientific and non-scientific staff are included to turn ideas and concepts into action. Accordingly, the MPSN aims to address all colleagues within the MPG because everyone is a crucial part in finding and implementing solutions for more sustainability. Scientific and non-scientific staff share the same work environment and the same desire to change the impact of their work regardless of their employee role and are thus on par with each other within the MPSN. Moreover, particular importance is given to the inclusivity of the network, for example, by attempting to represent all levels of staff (technical, scientific, and administrative) in the Steering Committee and in the network itself and by making all events and activities accessible to all members of the network. In the MPG, 9,297 non-scientific colleagues support 14,666 scientists (Max Planck, 2020). The MPSN consists of almost as many scientists (about 53\%, referred to as staff whose main task is to publish scientific articles) as non-scientific staff (about $47 \%$, referred to as staff whose main task it to support the scientific staff in their endeavor) (Figure 1D).

Similar to how we believe scientific diversity is necessary, we are also convinced that diversity in hierarchy and type of staff is necessary in order to achieve a change toward sustainability within the MPG. Colleagues at different hierarchical levels or positions are confronted with differential environmental aspects or can see different perspectives of the same issue. Within our network we practice a culture of equality, that is, opinions should solely be assessed on the basis of the statement itself and not on the speaker's position of authority.

\section{FOCUS OF THE MPSN'S WORK}

The MPSN aims to compile a catalog of recommendations for the implementation of sustainability measures on the institute level and throughout the MPG. This catalog shall be delivered to the Sustainability Groups and to the president of the MPG. In order to identify firstly the subjectively most important domains covering various aspects of academic and work life, the Steering Committee of the MPSN conducted a survey among its members. The survey included 10 domains and 116 measures rated on importance by 134 members. For the sake of overview and efficiency, the highest rated domains were chosen and similar domains grouped into the five clusters (i) Energy, (ii) Mobility, (iii) Supplies and Waste, (iv) Biodiversity and Food, and (v) Coordination and Assessment (Figure 2). Corresponding working groups were formed to create a first version of the catalog of recommendations, outlining and assessing each potential measure according to costs, feasibility, impact, and rating by network.

In addition to the five working groups, MPSN members have already implemented various MPG-wide initiatives pursued by ad hoc task forces: Starting off with a MPG-wide voluntary commitment to restrain from short-haul flights (about 480 signatories) and implementing and supporting virtual conferencing tools (Best Practice from the MPSN's Virtual Network Meeting). Further, aiming to influence policy makers, the network authored a position paper on "Compensation of $\mathrm{CO}_{2}$ Emission Caused by Travel Activity in the Max Planck Society" addressed to the General Administration of the MPG and a proposal for the Reform of the Federal Travel Expenses Act addressed to the German Government. 
A

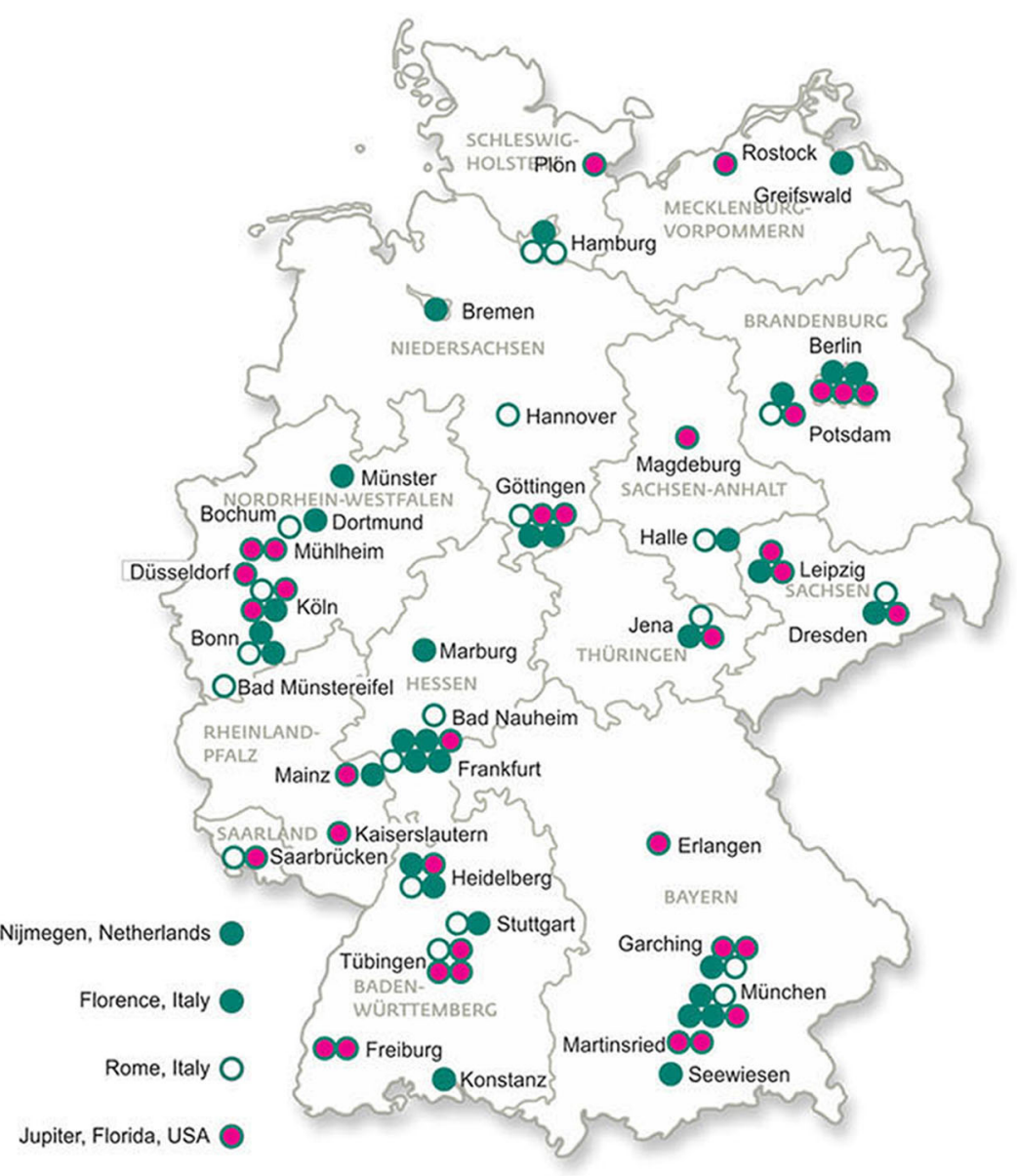

B

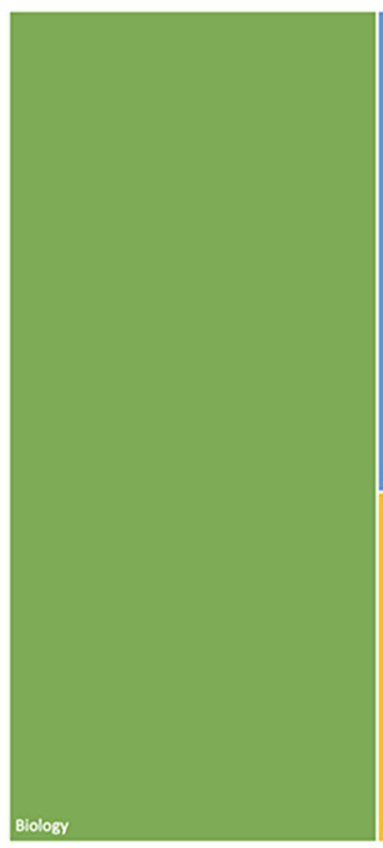

Field of expertise in the MPSN

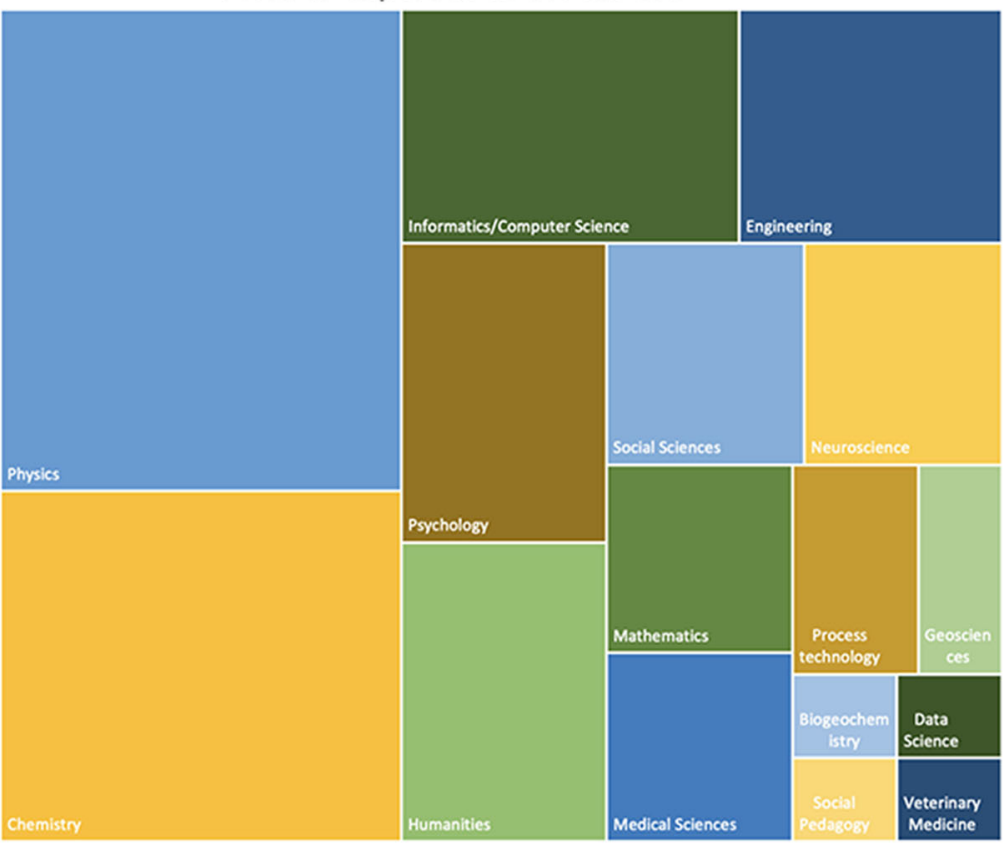

E Biology

" Physics

= Chemistry

- Informatics/Computer Science

a Engineering

I. Psychology

E Humanities

" Social Sciences

In Nouroscionco

a Mathematics

- Modical Scioncos

In Process technology

$=$ Geosciences

" Biogeochemistry

" Social Podagogy

a Data Science

a Veterinary Medicine

- Art / Musical Sciences

" Law

FIGURE 1 | Continued 


\section{C}

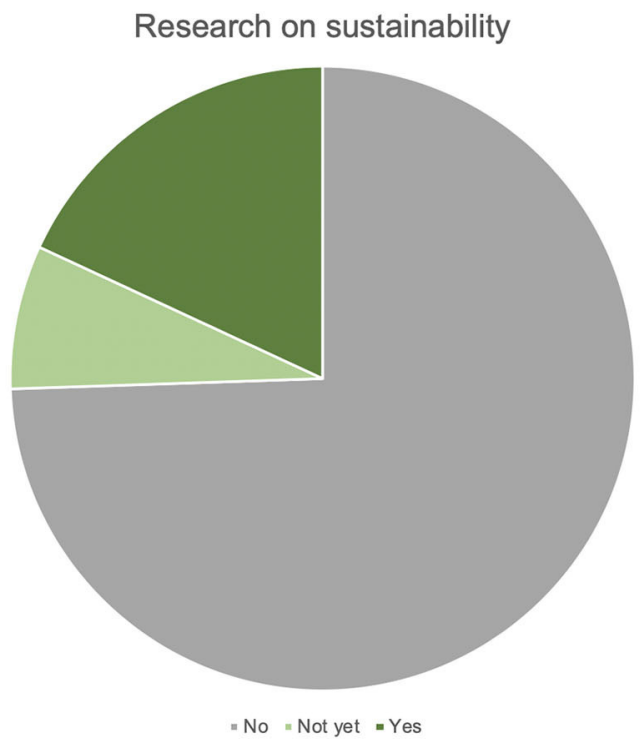

D

Position in the Max Planck Society

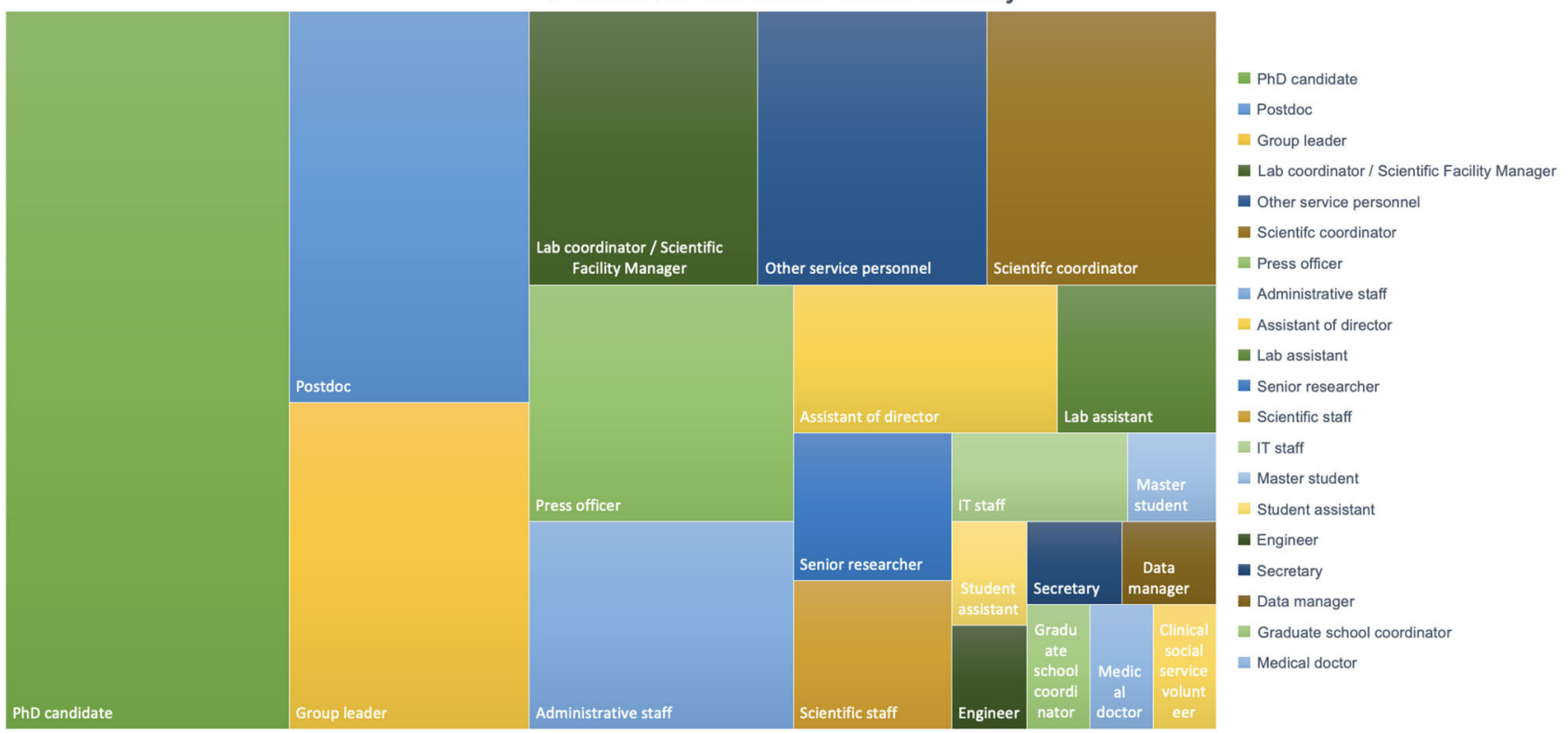

FIGURE 1 | Overview of current members of the MPSN (A) by location of Sustainability Groups across all Max Planck Institutes (MPIs) [pink: MPI with Sustainability Group and a Local Chair; green: MPI with network members; white: MPI without network members (B)] by their respective field of research (multiple answers possible) (C) by proportion of scientists carrying out research on sustainability and (D) by their functional roles within the MPG. Representative survey from July 2020 (response rate $n=111$ out of about 370 network members).

\section{EVALUATING ACTION}

The MPSN believes that before taking action, the measures to be implemented need to be carefully assessed. In the decision-making process of implementing sustainable practices, a careful assessment of each measure should be endeavored.

The primary metric for this assessment, is $\mathrm{CO}_{2}$-equivalent emissions, a metric that is for example useful in assessing the impact of travel, which much of the MPSN's action has focused on so far. As the network expands and begins addressing other domains such as the footprint of experimental laboratories and the ecological impact of equipment and infrastructure, other proposed metrics such as the multiple indicators used in lifecycle assessments (assessing environmental impacts associated with all the stages of the life-cycle), may become useful to assess diverse ecological impacts. Furthermore, an important first step in the evaluation strategy is to calculate a baseline $\mathrm{CO}_{2}$ 


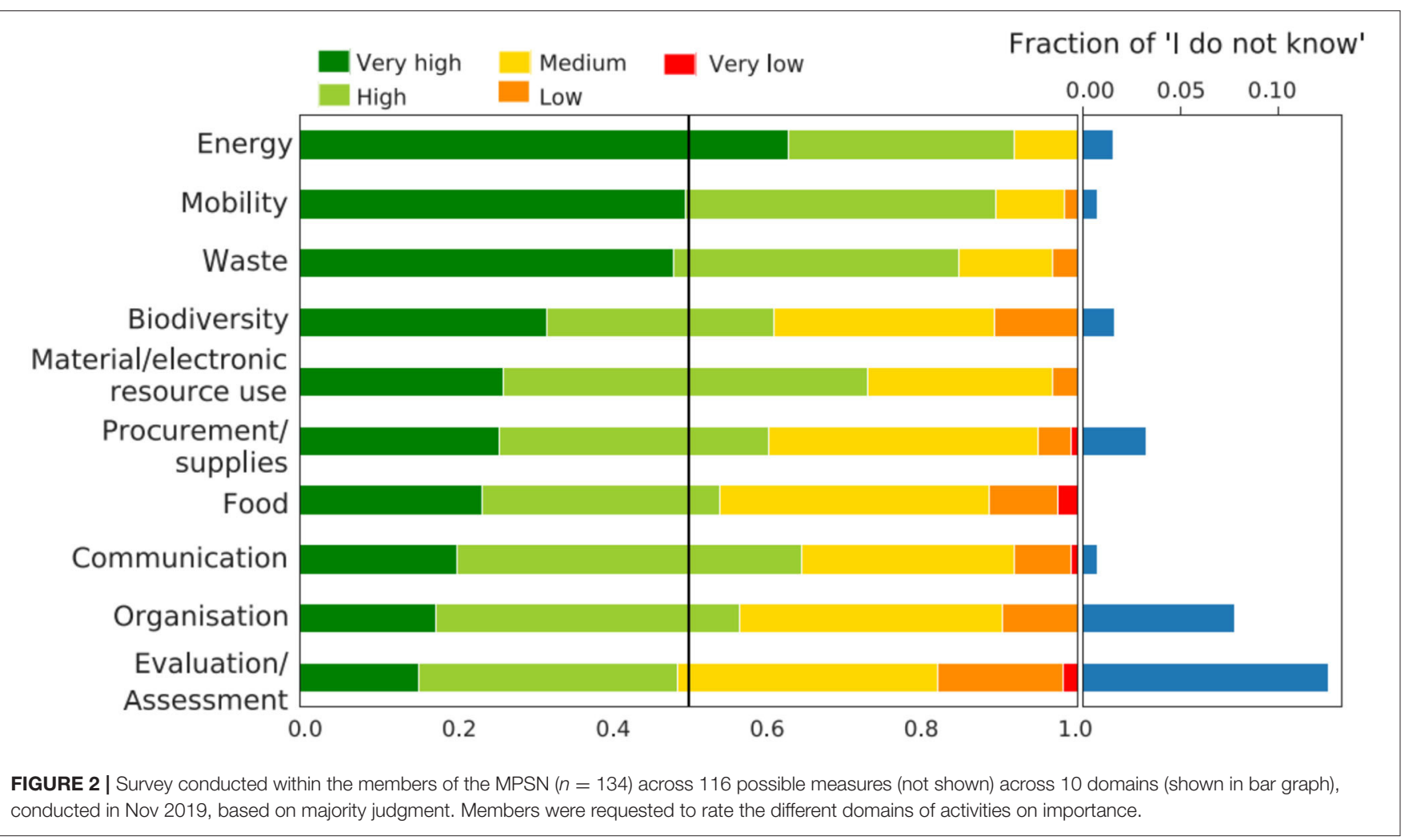

footprint of different institutes (carbon emissions reporting), which the network is currently working on. By repeatedly reestimating $\mathrm{CO}_{2}$ footprints over the next years, the MPSN will be able to assess to which extent the implemented measures have reduced emissions.

Beyond the impact of sustainability measures, the network's impact as a whole will be evaluated along multiple dimensions. On the level of the MPSN, an Advisory Board has been formed to counsel and monitor the Steering Committee and thereby ensure that the network's executive meets its internal goals. On the level of the MPG, the aforementioned working groups formulate the internal catalog of recommendations and keep track of which measures have been implemented to which extent. Collectively, the aim of these measures is to track the MPG's progress toward the goals set by the MPSN and to hold the MPSN accountable for its goals, quantifying this progress as much as possible, especially but not exclusively, using $\mathrm{CO}_{2}$-equivalent emissions as quantitative indicators.

\section{THE MPSN AND OTHER INITIATIVES FOR SUSTAINABILITY IN SCIENCE}

Although there are various initiatives across the globe (many of which the MPSN is partnered with), the MPSN stands out in terms of showing all of the following three attributes: being (i) a bottom-up network (ii) within a delimited national research society and (iii) addressing diverse aspects of sustainability through various organized subgroups. Similar initiatives in other science organizations overlap with some of the above attributes: For example, the employee-driven network EcoInfo within the French National Center for Scientific Research (CNRS) is committed to reduce the environmental impact of data processing at the various CNRS institutions (Montbroussous et al., 2019). The French grassroots initiative Labos1point5, reaches out to more diverse topics of sustainability as an international, inter-organizational network (Cluzel et al., 2020), as do also more top-down organized collectives between independent research institutions, like the University Alliance for Sustainability (Borman et al., 2019) or the International Sustainable Campus Network (Alshuwaikhat et al., 2017). Finally, there exist institutionalized projects to address changes toward sustainable practices within or among research institutions. In Germany, these comprise initiatives like the "Future Campus" at the Forschungszentrum Jülich (Rögener et al., 2017) or the project "Sustainability Management for non-university research institutions" (LeNa) (Daedlow et al., 2016). Through its bottom-up character the MPSN is distinct to the above-mentioned initiatives and to the prevalent employer-focused literature on the topic (Kim et al., 2016; Batista and Francisco, 2018; Lozano, 2018). The MPSN could provide further insight into organizational change management with regard to sustainability from within an organization. 


\section{DISCUSSION}

Following the official founding (May 2019) and democratic legitimization (statutes released Dec 2019) of the Max Planck Sustainability Network, the MPSN has positioned itself as an important actor within the academic sustainability movement. The network's long-term target is to contribute to the transition of the MPG and its associated institutes toward sustainable organizations and to facilitate this transition through interdisciplinarity, inclusive grassroots action, and through assessment and evaluation. To achieve this target, we investigate and enact measures across different domains (Energy, Mobility, Biodiversity and Food, Supplies and Waste). Some of these measures require behavior change from individual employees, which we will encourage through direct communication and through the participatory nature of our network. However, structural changes are also needed to support and foster such

\section{REFERENCES}

Alshuwaikhat, H. M., Abubakar, I. R., Aina, Y. A., and Saghir, B. (2017). "networking the sustainable campus awards: engaging with the higher education institutions in developing countries," in Handbook of Theory and Practice of Sustainable Development in Higher Education: Volume 2 World Sustainability Series. eds W. Leal Filho, C. Skanavis, A. do Paço, J. Rogers, O. Kuznetsova, and P. Castro (Cham: Springer International Publishing), 93-107.

Bachmann, G. (2016). "Science for sustainability-a societal and political perspective," in Sustainability Science: An Introduction, eds $\mathrm{H}$. Heinrichs, P. Martens, G. Michelsen, and A. Wiek (Dordrecht: Springer Netherlands), 359-367.

Balinski, M., and Laraki, R. (2007). A theory of measuring, electing, and ranking. Proc. Natl. Acad. Sci. U. S. A. 104, 8720-8725. doi: 10.1073/pnas.0702634104

Batista, A. A. D. S., and Francisco, A. C. D. (2018). Organizational sustainability practices: a study of the firms listed by the corporate sustainability index. Sustainability 10:226. doi: 10.3390/su10010226

Beringer, A., and Adomßent, M. (2008). Sustainable university research and development: inspecting sustainability in higher education research. Environ. Educ. Res. 14, 607-623. doi: 10.1080/13504620802464866

Borman, I., Rieckmann, M., Kummer, B., Niedlich, S., and Bauer, M. (2019). Sustainability Governance at Higher Education Institutions. Berlin: Freie Universität Berlin, Universität Vechta.

Cluzel, F., Vallet, F., Leroy, Y., and Rebours, P. (2020). "Reflecting on the environmental impact of research activities: an exploratory study." in 27 th CIRP Life Cycle Engineering (LCE) Conference (Grenoble).

Daedlow, K., Podhora, A., Winkelmann, M., Kopfmüller, J., Walz, R., and Helming, K. (2016). Socially responsible research processes for sustainability transformation: an integrated assessment framework. Curr. Opin. Environ. Sust. 23, 1-11. doi: 10.1016/j.cosust.2016. 09.004

Douglas, H. E. (2009). Science, Policy, and the Value-Free Ideal. Pittsburgh: University of Pittsburgh Press.

Hagedorn, G., Kalmus, P., Mann, M., Vicca, S., Berge, J. V., den, Ypersele, J.P., et al. (2019). Concerns of young protesters are justified. Science 364, 139-140. doi: 10.1126/science.aax3807

Jean, K., and Wymant, C. (2019). Airborne in the era of climate change. Science 363, 240-240. doi: 10.1126/science.aaw1145

Kim, W., Khan, G. F., Wood, J., and Mahmood, M. T. (2016). Employee engagement for sustainable organizations: keyword analysis using social network analysis and burst detection approach. Sustainability 8:631. doi: 10.3390/su8070631

Klöwer, M., Hopkins, D., Allen, M., and Higham, J. (2020). An analysis of ways to decarbonize conference travel after COVID-19. Nature 583, 356-359. doi: 10.1038/d41586-020-02057-2 behaviors, and yet other measures need to be taken on the structural level alone. Taken together, these steps and the MPSN as a whole are aimed toward taking responsibility for the ecological impact of our work and to furthering the role of sustainability and climate action within the scientific community.

\section{DATA AVAILABILITY STATEMENT}

The raw data supporting the conclusions of this article will be made available by the authors, without undue reservation.

\section{AUTHOR CONTRIBUTIONS}

TF, JM, EM, JHR, JDR, and JS: first draft. MH, SL, EM, and JS: revisions. All authors: contributed to the article and approved the submitted version.

Langin, K. (2019). Climate scientists say no to flying. Science 364, 621-621. doi: 10.1126/science.364.6441.621

Lozano, R. (2018). Proposing a definition and a framework of organisational sustainability: a review of efforts and a survey of approaches to change. Sustainability 10:1157. doi: 10.3390/su10041157

Max Planck, G. (2020). Annual Report 2019. Available online at: https://www.mpg. de/annual-report (accessed July 30, 2020).

Montbroussous, B., Schaeffer, J., Moreau, G., Berthoud, F., and Feltin, G. (2019). Calculate the carbon footprint of your IT assets with EcoDiag, an EcoInfo service. arXiv:1912.06038 [cs].

Nature Nanotechnology. (2019). Scientists should explore alternatives to flying. Nat. Nanotechnol. 14:813. doi: 10.1038/s41565-019-0546-3

Ripple, W. J., Wolf, C., Newsome, T. M., Barnard, P., and Moomaw, W. R. (2020). World scientists' warning of a climate emergency. BioScience 70, 8-12. doi: 10.1093/biosci/biz088

Rogelj, J., Shindell, D., Jiang, K., Fifita, S., Forster, P., Ginzburg, V., et al. (2018). "Mitigation pathways compatible with $1.5^{\circ} \mathrm{C}$ in the context of sustainable development," in Global Warming of $1.5^{\circ}$ C. An IPCC Special Report on the Impacts of Global Warming of $1.5^{\circ} \mathrm{C}$ Above Pre-industrial Levels and Related Global Greenhouse Gas Emission Pathways, in the Context of Strengthening the Global Response to the Threat of Climate Change, Sustainable Development, and Efforts to Eradicate Poverty, eds V. Masson-Delmotte, P. Zhai, H.-O. Pörtner, D. Roberts, J. Skea, P. R. Shukla, A. Pirani, W. Moufouma-Okia, C. Péan, R. Pidcock, S. Connors, J. B. R. Matthews, Y. Chen, X. Zhou, M. I. Gomis, E. Lonnoy, T. Maycock, M. Tignor, and T. Waterfield (In Press), 93-175.

Rögener, W., Stettien, A., and Rother, A. (2017). Annual Report 2016. Forschungszentrum Jülich. Available online at: https://www.fz-juelich.de/ SharedDocs/Downloads/PORTAL/EN/publications/annual-reports/annualreport-2016.pdf (accessed September 10, 2020).

Rosen, J. (2017). Sustainability: a greener culture. Nature 546, 565-567. doi: 10.1038/nj7659-565a

Vogt, M., and Weber, C. (2020). The role of universities in a sustainable society. Why value-free research is neither possible nor desirable. Sustainability 12:2811. doi: 10.3390/su12072811

Conflict of Interest: The authors declare that the research was conducted in the absence of any commercial or financial relationships that could be construed as a potential conflict of interest.

Copyright (C) 2020 Fardet, Hütten, Lohmann, Medawar, Milucka, Roesch, Rolfes and Schweizer. This is an open-access article distributed under the terms of the Creative Commons Attribution License (CC BY). The use, distribution or reproduction in other forums is permitted, provided the original author(s) and the copyright owner(s) are credited and that the original publication in this journal is cited, in accordance with accepted academic practice. No use, distribution or reproduction is permitted which does not comply with these terms. 